\title{
HTLV-1 Antibody
}

National Cancer Institute

\section{Source}

National Cancer Institute. HTLV-1 Antibody. NCI Thesaurus. Code C71691.

An antibody produced by B lymphocytes in response to human T-cell leukemia virus type 1 infection. 